\title{
Anthropology and Art in State of Exception: The Evolution of an Exhibition
}

\author{
Amanda Krugliak $^{1}$ and Richard Barnes ${ }^{2}$
}

This essay provides an in-depth look into the development and evolution of the exhibition State of Exception, created by artist and curator Amanda Krugliak and photographer and artist Richard Barnes, in collaboration with anthropologist Jason de León. The exhibition features items left behind by migrants in the Arizona desert on the U.S.-Mexican border, such as backpacks, clothing, and personal items. Through careful curation and the inclusion of video and sound materials, State of Exception adds a unique and intimate perspective to ongoing and often contentious conversations about clandestine border crossings. [Article copies available for a fee from The Transformative Studies Institute.E-mail address: journal@transformativestudies.org Website: http://www.transformativestudies.org $@ 2020$ by The Transformative Studies Institute. All rights reserved.]

KEYWORDS: U.S.-Mexico Border, Arizona Desert, Undocumented Migration, State of Exception, Anthropology and Art.

The exhibition State of Exception is a collaborative endeavor between artist/photographer Richard Barnes, anthropologist Jason De León, and myself in the role of artist and curator. It has involved a two-year engagement and conversation in which we considered the best ways to curate the objects from Jason De León's Undocumented Migration Project. Since 2008, De León and his team of students/archaeologists have been working on the border between Arizona and Mexico, collecting and cataloging the detritus that is cast off and left behind by migrants as they cross into the United States.

\footnotetext{
${ }^{1}$ Amanda Krugliak is an artist, curator, and arts administrator at the Institute for the Humanities, University of Michigan.

${ }^{2}$ Richard Barnes is an award-winning photographer and artist.
} 
Theory in Action

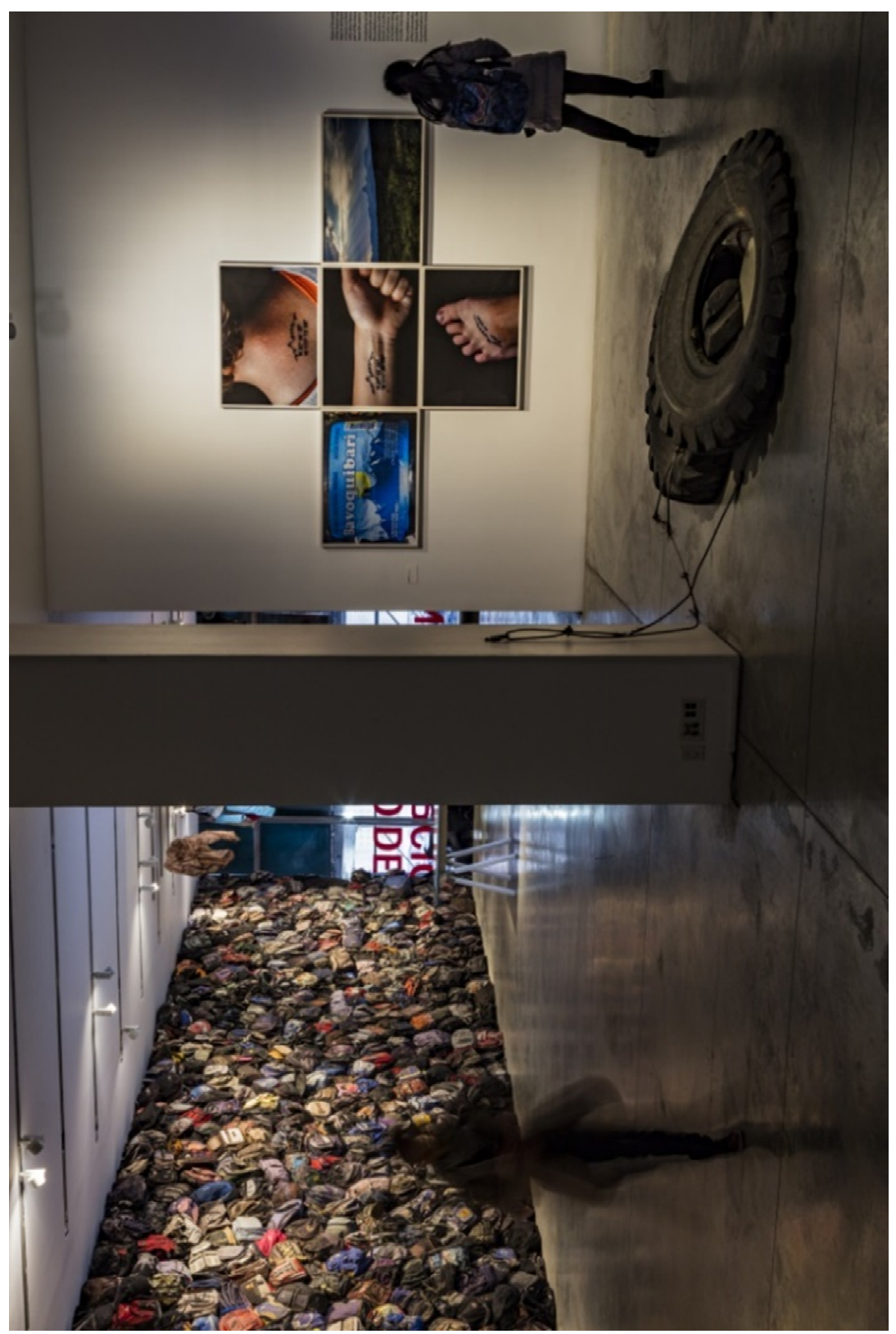

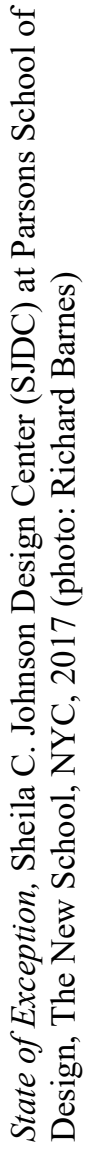




\section{Amanda Krugliak and Richard Barnes}

Originally presented at the University of Michigan Institute for the Humanities Gallery, and most recently at the Museum of Contemporary Art Detroit (MOCAD), ${ }^{3}$ our exhibition takes into account the human experience within the frame of De León's research and methodology. In putting together the installation, we have always thought about this project conceptually and aesthetically rather than strictly anthropologically. The videos, photographs and objects in the exhibition represent our impressions informed by the perspectives and the fieldwork carried out by De León and his crew. Of course, the political implications of what we were dealing with were never far from our minds.

It was significant to us that we each came to the project from a different point of entry with varying experiences and relationships to the material, thus offering the opportunity to take the exhibition to a unique, perhaps unexpected and provocative place. It was this assemblage of unlike elements and perspectives that literally activated the space. State of Exception is the result of an organic and inductive inquiry. It continues to evolve and mature with each new installation. The Exhibition title, State of Exception, is a reference to the political theory of the same name. This theory was first outlined by Carl Schmitt and later elaborated by Italian political philosopher Giorgio Agamben (2005). As Jason De León describes,

State of Exception refers to the process whereby sovereign authorities declare emergencies, often with the stated goal of protecting the state, in order to suspend the legal protections afforded to individuals while, at the same time, unleashing the power of the state upon them. This theory has been a particularly salient concept for those working on the margins of nation states, where the tensions of sovereignty and state security are both geographical and visibly acted out on a daily basis as governments seek to keep out "illegal aliens" (i.e, non-citizens) through a variety of extraordinary measures. We chose to call the exhibit State of Exception because we find the vast Sonoran Desert and the many social, political, and economic processes related to migration that occur there to be both exceptional (uncommon, not ordinary, deviating from the norm) and representative of the ways which

\footnotetext{
${ }^{3}$ The work was also exhibited at ARtprize, Grand Rapids, Michigan, in 2015, where it was awarded the Latinx Spirit Award. In February 2017, the exhibition was installed at Parsons Sheila C. Johnson Design Center, NYC, where it included additional interviews of asylum seekers, as well as images of their journeys taken on pocket cameras provided by De León.
} 
sovereign powers can justify treating non-citizens in exceptional ways. (State of Exception catalog)

More philosophically, we felt it expressed this place of limbo and perhaps in seeming a contradiction to the exhibition title, a condition of "statelessness." An exceptional in-between place, neither in Mexico or the United States, unresolved and vulnerable as migrants often find themselves. The extraordinary journeys taken by so many, the endurance of those under exceptional circumstances, the complexity of a situation, and the asking for understanding and consideration of human life under exceptional circumstances.

In 2012, we joined De León in Arivaca, Arizona, accompanying him into the debris fields scattered across the desert floor. Throughout the process of the exhibition, the thread of first impressions from this visit carried through to the final installation. Barnes recorded video on location along the border at night, photographing in the field, and interviewing students about their experiences. Not long after the trip, De León and his students found a woman, "Marisol," dead in the desert during their field work. They sat with her for hours until the authorities removed the body. This unexpected and profoundly affecting occurrence deeply impacted all those involved in the research and impending exhibition. The objects curated were now rooted firmly in the present, representing real stories and people, and this clear distinction inevitably gave State of Exception an active rather than passive voice, offering the opportunity for awareness, as well as the opportunity for response and action. The foundation for the installation was based upon a series of ongoing questions:

What do the objects stored in U-Haul boxes in De León's office stand in for?

Is a backpack from the desert as affecting as an object as a suitcase from the Holocaust?

How can human suffering be a point of comparison?

Do the discarded backpacks contoured to individual bodies dumped in the desert represent human strife or simply a commodity one might purchase at a sporting goods store?

Are the barely "there" remnants of ID cards, bus tickets and photographs profound or mundane? 


\section{Amanda Krugliak and Richard Barnes}

Over many months, we continued to think about and talk these issues over as a collaborative team, working towards a challenging and provocative exhibition. There is no question that the work of De León's Undocumented Migration Project is charged, and thoroughly engaging in its timeliness and relevance to politics and culture. For some it is a zeitgeist, representing a clear path for border activism. For others, the objects retrieved from the desert serve as no more than detritus, or quite simply trash unworthy of collection and study. We wanted to acknowledge these conflicts in interpretation and build an exhibition that asks more questions than it answers.

Our objective with the exhibition was to create an installation concerned with aesthetics, materiality, and practice. Yet, the politics were also undeniable. From our perspective as a collaborative team, the exhibition State of Exception attempts to consider the journey of migrants through the deserts of Arizona from all sides, like a puzzle, turning it over, and then again. It emphasizes the ambiguity and complexity of a situation that is as ongoing and endless as the border fence itself. It is determined as much by geography and race as by people smugglers, Border Patrol, and Samaritans. It is rooted in hopefulness and dreaming, as well as commerce and enterprise. And although exceptional in terms of its particularities, it is as significant as any other cultural migration.

With all of these considerations in constant play, after many months of critical inquiry, the key elements of the exhibition emerged. Thematically, the wall of backpacks became the focal point, representing both the individual as well as the collective experience, suggestive of what it must be like to cross the border illegally, seeking something better than one's respective countries can offer. The backpacks serve as figurative representations, gestural references of the body, the weightiness, the burden, each with its own unique quality. The wall differs from other collective cultural installations, in that it is not meant as a memoriam to the dead, (although there is always the suggestion of death in the desert), but rather about the living... referencing the visceral, tactile, sensory experience of carrying everything you own on your back.

They are intimate, but at the same time imposing, inhabiting the room rather than simply being on display. The backpack logos from American and Mexican TV, sports clubs, fashion houses etc. are literally emblematic of the global economy and the influence of the United States in and endless situation with seemingly unsolvable questions around undocumented migration, emphasizing the blurry line between us all. 


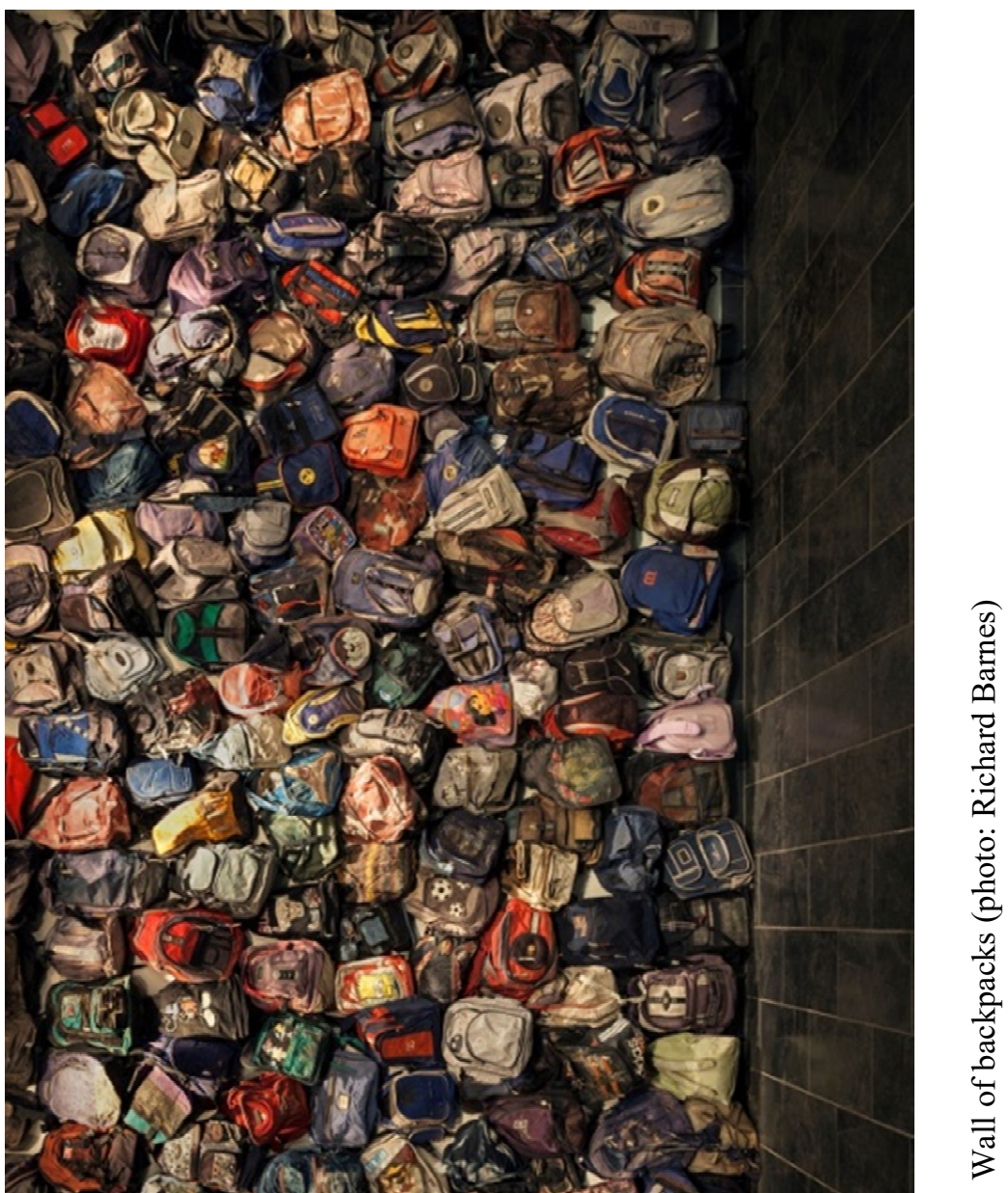




\section{Amanda Krugliak and Richard Barnes}

In our first presentation of State of Exception at the smaller Institute gallery, the backpack installation was immersive, forcing viewers to experience them up close, installed on two walls, in a corner configuration; they created an enclosure, a sanctuary-like experience, reflective, sensory. This gave the illusion that the backpacks were coming forward spatially, rather than contained on the wall. They inhabited the room. Their smells and weathered textures suggested human life in the desert.

In our recent re-installation at MOCAD, a more industrial urban space, the vastness of the wall of backpacks conceptually was in keeping with the expanse of desert, and the sheer number of crossings. Philosophically, this alluded to freedom and opportunity as well as unpredictability and uncertainty. The openness of the space with high ceilings determined the scale of the wall. The number of backpacks $(600+)$ displayed was double that of our original conception. This ongoing process of re-thinking and re-imagining the exhibition, determined by the context of the space and its relevance to community is an integral part of the project for our collaborative team. At no point in touring the exhibition do we want the project to become staid or static. We hope to continue engaging with the materials, making room for new elements, and editorial decisions, each new iteration of the exhibition informing the next.

Our curation of the objects left behind by undocumented migrants in the desert represents our attempt to rethink cultural objects and how we collect, curate and organize them, bringing this migration into a broader overall conversation, with the refusal to make the objects inanimate. In our initial thinking it was important to us that no one object be elevated, valued or fetishized more than another. The mundane qualities of the toothbrushes and the Border Patrol handcuffs tell us as much about any individual's story as the baby bottles and rosaries. All are fragments of a story, rather than affirmations of one way to tell it, or one version, or complete certainty in that version. We've placed objects in vitrines to reference more traditional museum display of other cultural collections historically, yet, we organized them in mass...as an ephemeral gesture, a sweep of objects emphasizing the transient nature of this migration, emphasizing how the passage of time changes the way we perceive the importance and value of artifacts and human experiences. We consciously made an effort to curate the objects in different contexts, to extend the breadth of the conversation... how we think about objects, and in turn undocumented migration. 
Theory in Action

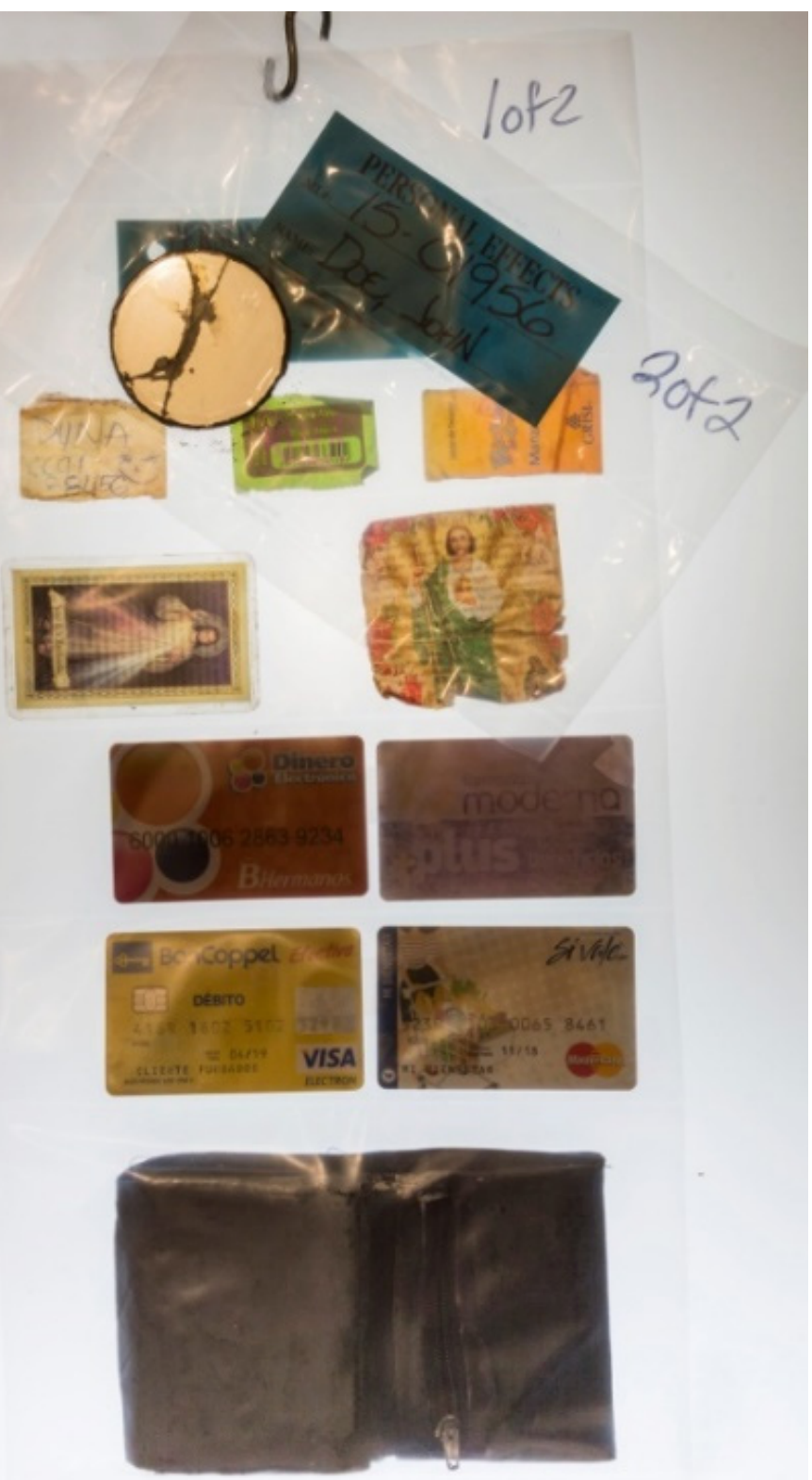

Artifacts (photos: Richard Barnes) 
Amanda Krugliak and Richard Barnes

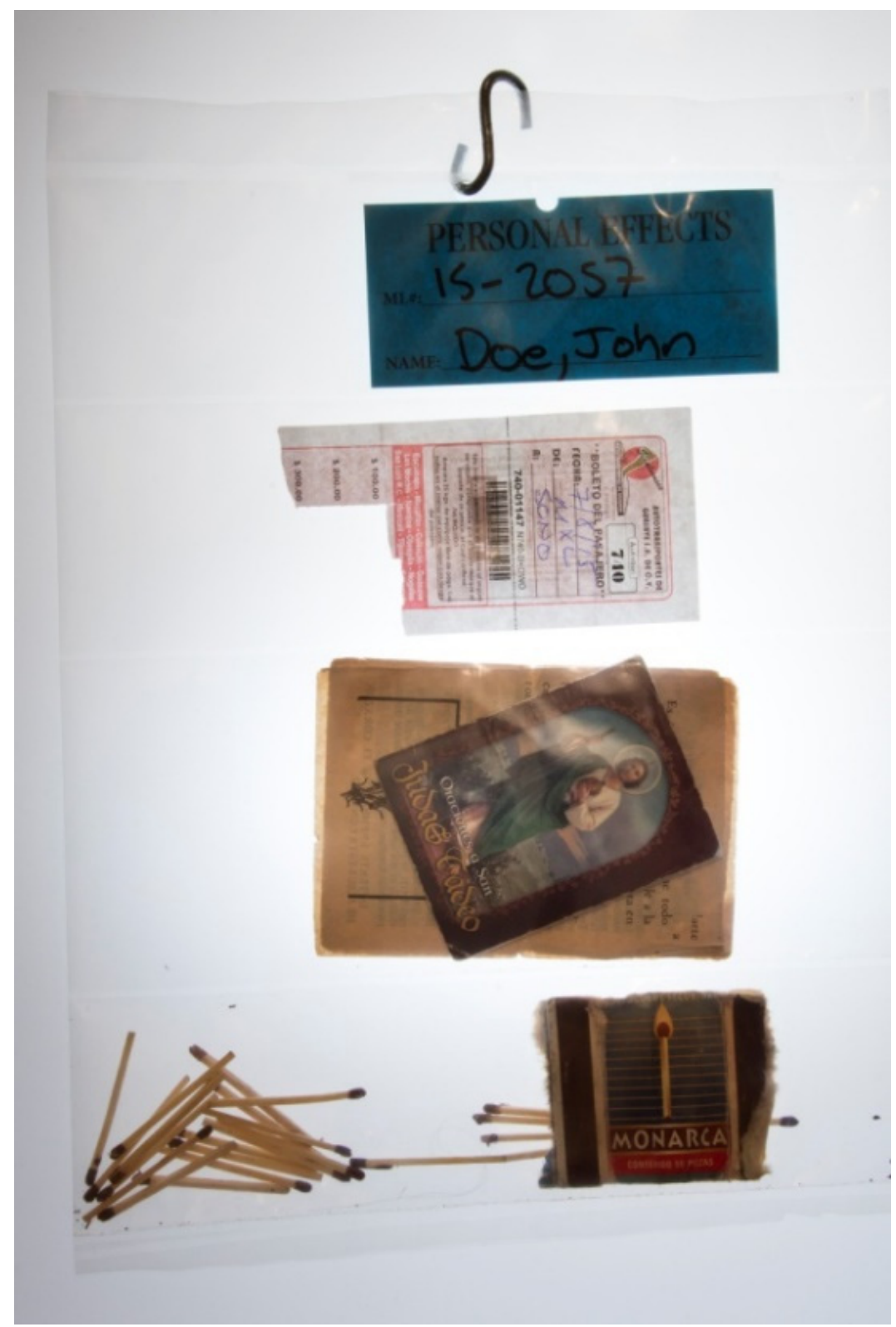

Artifacts (photos: Richard Barnes) 
As an example, a makeshift "surrender flag" found in the desert, comprised of a sweatshirt tied to a branch, was dramatically lit and choreographed on a wall for the original installation. This evoked the memory of artifacts from history, perhaps even the Civil War. Yet, for the MOCAD installation, the same object was casually propped against a wall...accessible, more about the everyday and our familiarity with the object, which offered a completely different perspective.

Two primary video projections in the exhibition present the border fence. The first is shot at night during a rainstorm with the intended point of view of a border patrol officer through a car windshield. This is juxtaposed with a perpendicular view out the side window of the slats of the border fence looking into Mexico from the U.S. side. The video projections are dominant thematically, ever present. In the original installation at the Institute, the projections occupied one corner of the gallery playing off the backpacks arranged across the room in a similar corner configuration. For the MOCAD installation, the videos were relegated to their own space, on opposite walls, more contemporary and minimal whereas the Institute configuration was more personal. The strangely misleading landscape, with an abundance of rain in the desert with no water for the migrants to drink is ironic in its evocation of both the risks taken and the dangers of the desert crossing.

The recent inclusion of audio interviews presented significant challenges, and we are still finding appropriate solutions. In the time since the start of our first exhibition and the onset of our collaboration, De León has become more directly involved with migrants and their families. Since finding the body of "Marisol" in the desert, De León has made contact with her family, learning recently of another cousin, José, now missing, and we are committed to incorporating audio and objects related to these more personal stories.

As artists, the question remains how to incorporate these narratives and new objects thoughtfully...still preserving the ambiguous and nuanced character of the curation, while at the same time leaning towards activism. How can we incorporate individual accounts, and still preserve the collective experience? How do we appropriate the interviews without venturing into the territory of re-enactment? For now we have chosen to play fragments of the original interviews in Spanish, which conceptually seems consistent with the overall structure and authenticity of the project. The exhibition has succeeded in honoring this exceptional migration through the presentation of the objects, and in doing this, the exhibition now insistently calls for voices...the direct accounts of migrants, a natural progression of the presentation. 


\section{Amanda Krugliak and Richard Barnes}

A video projected on the floor from above became the third primary element for the overall installation of State of Exception. This immersive pathway offered viewers the experience of walking across the debris fields left by migrants on the US side of the border as they change their clothes and try to "blend in," hoping to avoid detection by the border patrol. The fields of cultural artifacts they cast off in the desert consisting of the aforementioned backpacks, water bottles, deodorant and toothpaste tubes, shoes, etc. references the methodology of the work of anthropologist De León and the experience of what a "layover" site is like. At the same time, conceptually, experiencing the video sets viewers off balance, disarming them. This initial disorientation thrusts viewers into a new space, and a new way of seeing.

Finally a video grid, composed like a John Cage experimental score, takes six interviews done on site with De León 's field school participants and collapses and layers them over one another. The documentary-style video portraits of each individual become swatches of data in themselves. The voices overlap, sometimes chaotic, yet at other moments, they offer up important facts or impressions. At times everyone speaks simultaneously, then maybe one or two and there is a clarity arising out of this "babel" of expression. It might be a student discussing what it's like to come upon a body decomposing in the desert sun or another participant whose own parents are "illegals" in the country of his birth. This combination of elements evokes the difficulty and the conflicting views surrounding immigration. The impressions of the anthropologist and field study participants again establish the framework of method and research.

Specific to the MOCAD installation were photographs that Barnes created while on location during his time in Arivaca, Arizona. These felt appropriate in the context of MOCAD in Detroit. Their graphic impact made sense with the scale of the vast wall of backpacks and the oversized video projection on the warehouse floor. Photography as a medium also felt contemporary and relevant to the young urban Detroit community. The photographs of commemorative tattoos marking desert coordinates on the bodies of the field school students spoke to a young generation influenced by pop culture, with some freedom from the associations of World War II and the Holocaust. Surprisingly for us, the very suggestion that this undocumented migration was part of any conversation with these images reminiscent of the Holocaust proved highly controversial to many viewers, verging on complete intolerance. The unsettling nature of these images and the responses they evoked illustrate the charged complexity of undocumented migration, and the investments of those that become a part of this issue either directly or peripherally. 


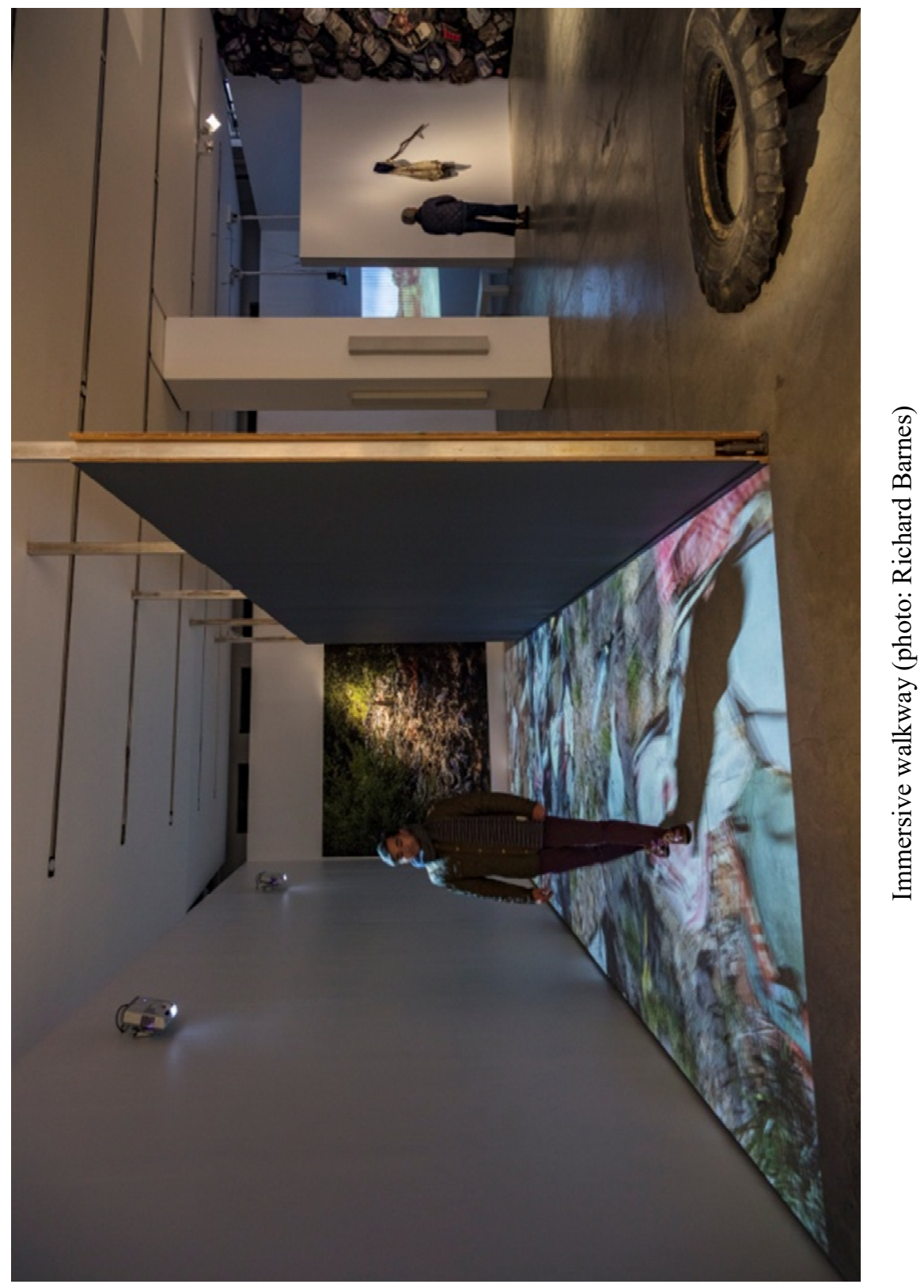




\section{Amanda Krugliak and Richard Barnes}

It is our hope that State of Exception will continue to travel and be reinstalled at additional venues, recognizing that each community and place geographically re-defines the exhibition, and changes it. As De León 's research continues to include actual migrant interviews, which weren't available at the onset of this exhibition, the exhibition is also changing, incorporating the migrant stories in their own voice. Photographs taken by migrants with pocket cameras during their crossings will also be represented. Using our initial installation as a model, we look forward to always the next step, what can evolve and happen in the process here and elsewhere, considering undocumented migration framed within this remarkable research.

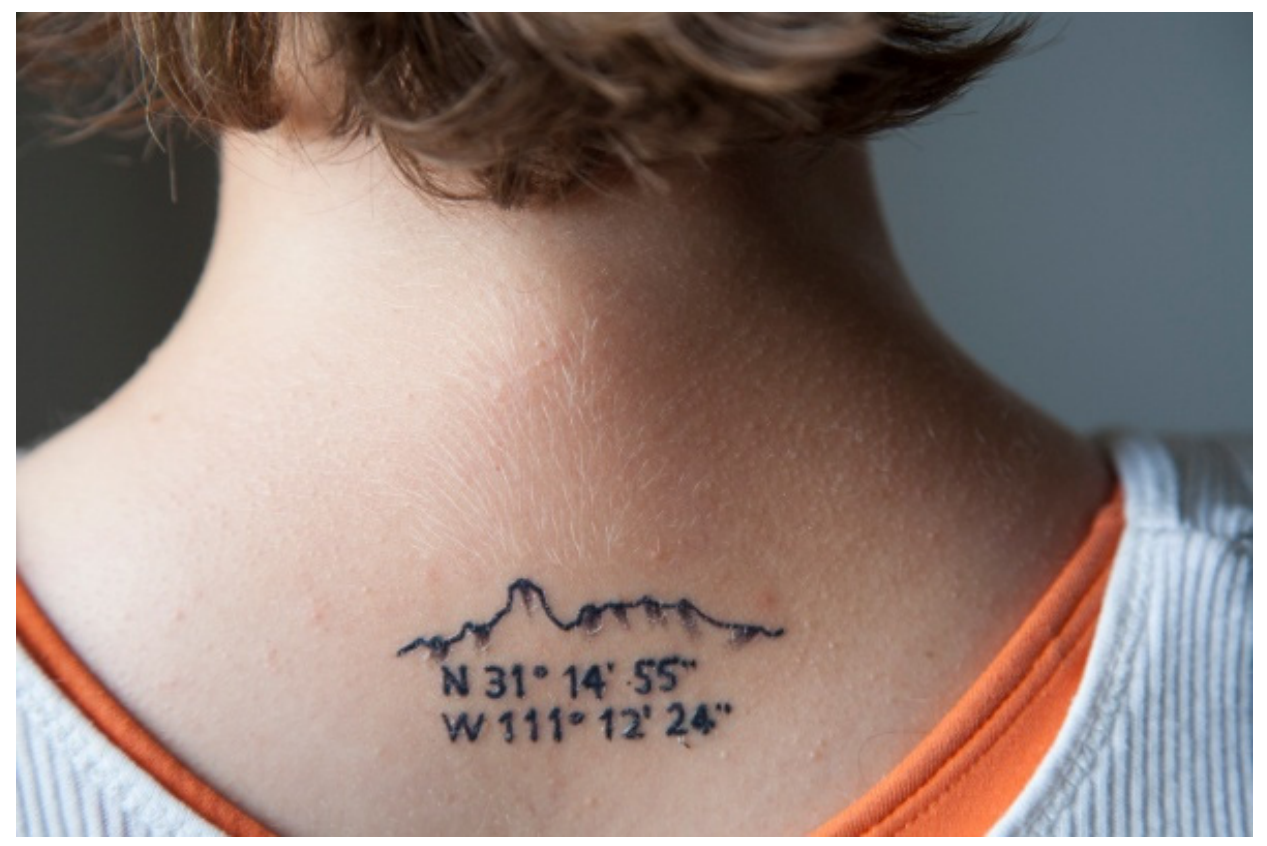

Tattoos marking desert coordinates (photo: Richard Barnes) 
Theory in Action

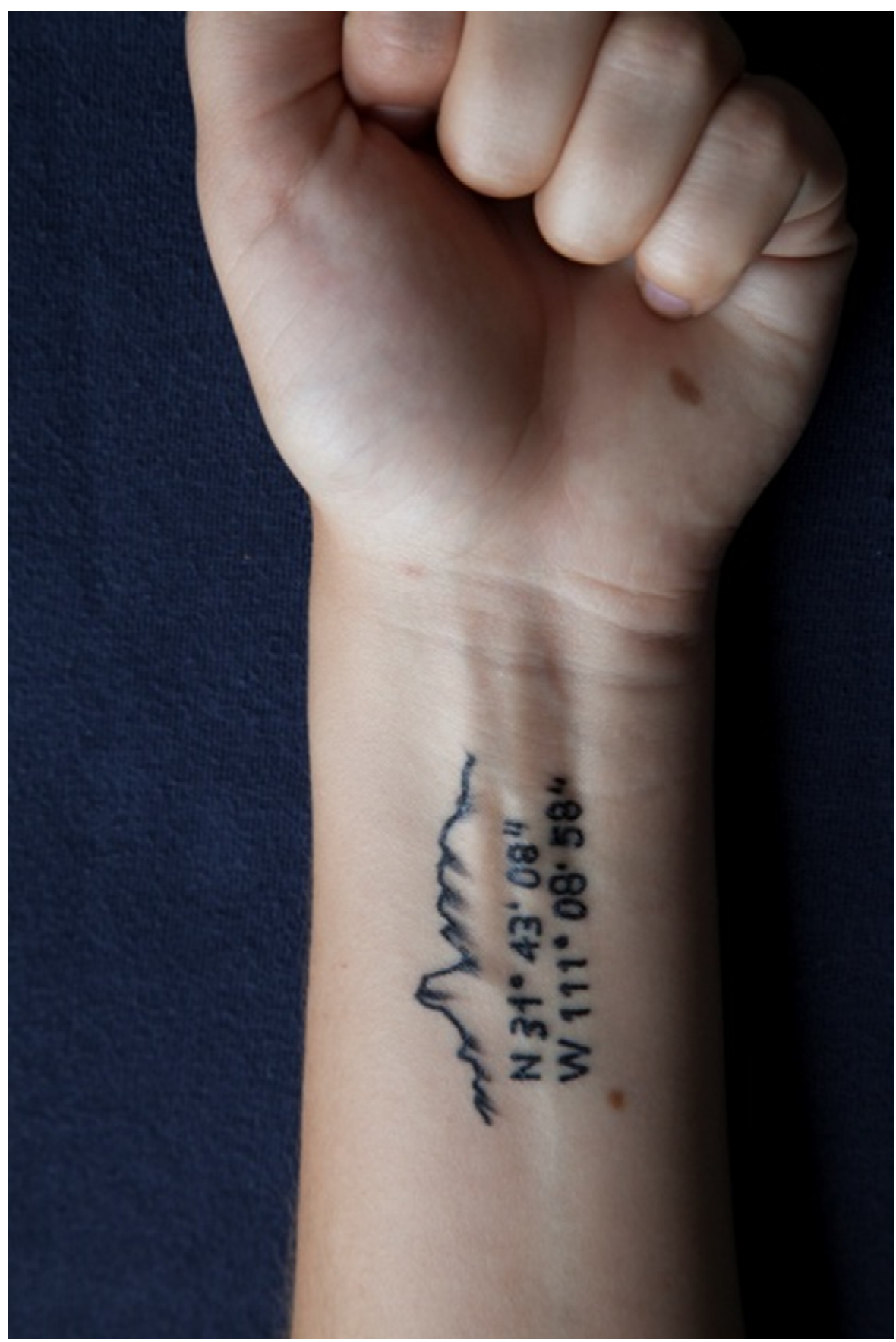

Tattoos marking desert coordinates (photo: Richard Barnes) 


\section{Amanda Krugliak and Richard Barnes}

\section{UPDATE, 2020}

Although we are no longer touring the exhibition or collaborating, the show did travel after MOCAD and during the time in which this article was written, with three more iterations in the United States, as well as two features in the NYT, and finally resulting in the images from the show running in small town newspapers across the globe, post 2016 election, making an indelible imprint.

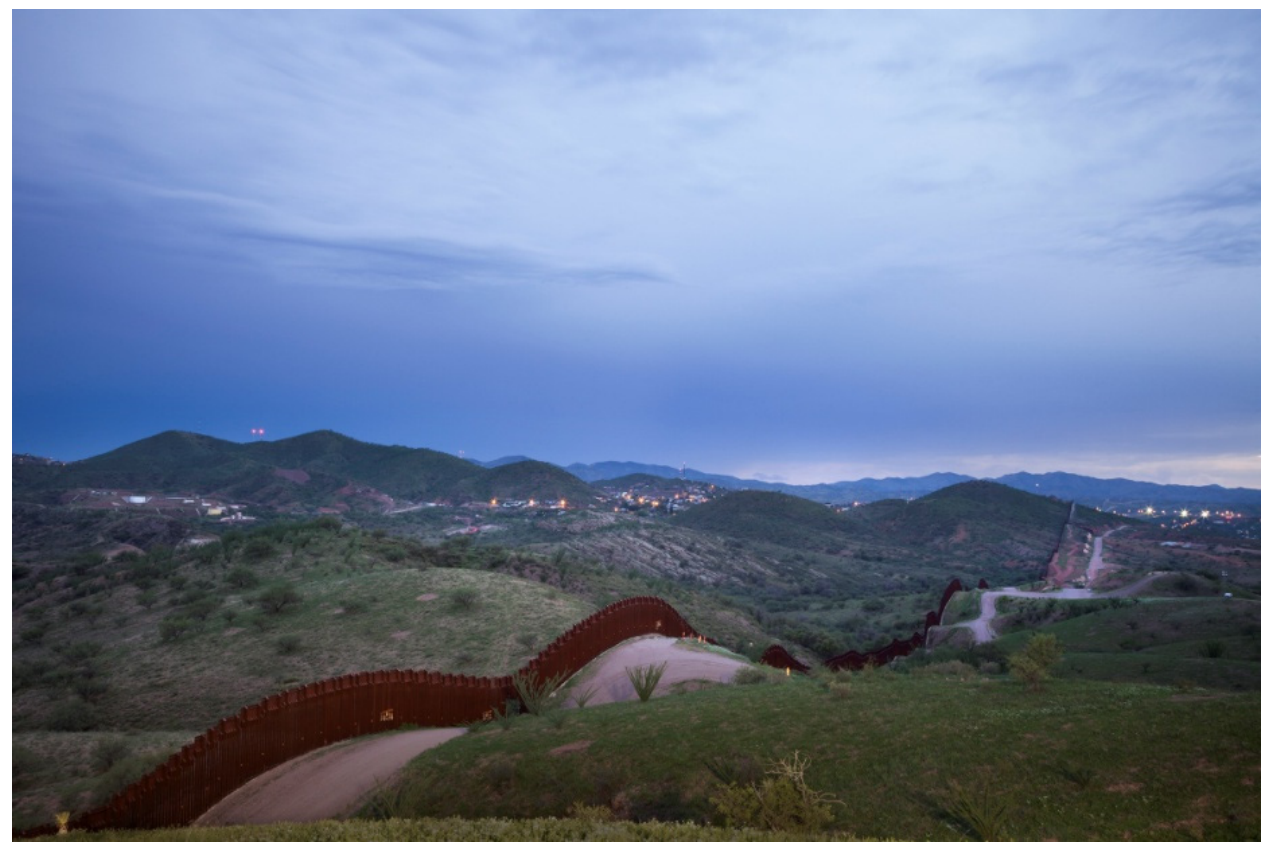

Border wall Nogales, Arizona (photo: Richard Barnes) 